\title{
Syndromic Rhyme
}

\author{
Abdul Haque M. Quraishi
}

Received: 15 September 2010 / Accepted: 13 January 2011/Published online: 15 April 2011

(C) Association of Surgeons of India 2011

I found the poem titled "Syndromic Rhyme" by Sanjeev Narang [1] very interesting. The author does not intend to present the use of poetry beyond being a memory peg to hang medical facts. However, poetries have been used as pedagogical catalysts as also to raise ethical sensitivities among students and nurses. There have been few studies regarding poetry-based medical education. One such in depth study analyzed learners attitudes towards poetrybased education. It revealed that the poetry sessions may provide an environment for emotional exploration, which could broaden understanding of self and others [2]. There is perhaps only one article which describes an attempt by a professor to teach diagnosis through poetry [3]. We at the Association of Surgeons of India, Nagpur chapter have been conducting a state level surgical quiz since last 10 years for undergraduate students. The most interesting part for the students is the cryptic clues round. Herein we provide cryptic clues to the participants. There is a distracting theme too, but those who focus on the clues unravel the answer soon enough, although they may not be required to use all the clues. It is a learning experience with an entertainment quotient for the students. It is an enriching experience for the quiz master too. The clues lead you to a surgical condition, procedure, or a complication. Below is given one such cryptic clues question and the answer and its explanation follows.

Lee was handed the ball,

To remove Chaminda once for all,

A. H. M. Quraishi $(\bowtie)$

Department of Surgery, Government Medical College, Nagpur, India

e-mail: am_quraishi@hotmail.com
No sharp cutter was used for his fall,

All tail-enders were out without scoring,

Twice in 3 months boss, No kidding!

\section{Answer No Scalpel Vasectomy (NSV)}

Explanation For the unwary the theme of cricket can be quite distractive. It seems Brett Lee; the Australian bowler is not required to use sharp cutters from his repertoire to get rid of Chaminda Vas, the Lankan bowler, who is on strike. The same fate befalls the other tail-enders. The correct explanation however is that Lee is for Dr Shinqiang Lee who developed the No scalpel vasectomy technique in 1974 in China. Handing over the ball and removing Chaminda (Vas) without a sharp cutter, has been used symbolically for no scalpel vasectomy. The reference to tail-enders is for sperms and that ideally azoospermia has to be demonstrated twice after 3 months of vasectomy (WHO recommendation) after which other methods of contraception may be omitted. No kidding has obviously been used as a reference to the successful outcome of the procedure. Incidentally, this question was answered correctly by one of the teams.

\section{References}

1. Narang S (2010) Syndromic rhyme. Indian J Surg 72:170

2. Foster W, Freeman E (2008) Poetry in general practice education: perceptions of learners. Fam Pract 25(4):294-303

3. Moulton-Barrett D (1984) Teaching diagnosis through prose and poetry. Can Med Assoc J 130(7):928-929 